\title{
Immune Checkpoint Inhibition in Hepatocellular Carcinoma: Basics and Ongoing Clinical Trials
}

\author{
Masatoshi Kudo \\ Department of Gastroenterology and Hepatology, Kindai University Faculty of Medicine, Osaka-Sayama, Japan
}

\section{Key Words}

Hepatocellular carcinoma $\cdot$ Immune checkpoint

inhibitors · PD-1 antibody · PD-L1 antibody · CTLA-4

antibody $\cdot$ Nivolumab $\cdot$ Pembrolizumab

\begin{abstract}
Clinical trials of antibodies targeting the immune checkpoint inhibitors programmed cell death 1 (PD-1), programmed cell death ligand 1 (PD-L1), or cytotoxic T-lymphocyte-associated protein 4 (CTLA-4) for the treatment of advanced hepatocellular carcinoma (HCC) are ongoing. Expansion cohorts of a phase I/II trial of the anti-PD- 1 antibody nivolumab in advanced HCC showed favorable results. Two phase III studies are currently ongoing: a comparison of nivolumab and sorafenib in the first-line setting for advanced HCC, and a comparison of the anti-PD-1 antibody pembrolizumab and a placebo in the second-line setting for patients with advanced HCC who progressed on sorafenib therapy. The combination of anti-PD-1/PD-L1 and anti-CTLA-4 antibodies is being evaluated in other phase I/II trials, and the results suggest that an anti-PD-1 antibody combined with locoregional therapy or other molecular targeted agents is an effective treatment strategy for HCC. Immune checkpoint inhibitors may therefore open new doors to the treatment of HCC.
\end{abstract}

(c) 2017 S. Karger AG, Basel

\section{KARGER}

๑) 2017 S. Karger AG, Basel

E-Mail karger@karger.com

www.karger.com/ocl

\section{Introduction}

Since immune checkpoint inhibitors were first reported in 2010 [1] and 2012 [2], they have exceeded expectations in clinical studies, the results of which indicate that these agents are highly effective (even in patients with advanced or metastatic liver cancer). The goal of previous cancer immunotherapy has so far been to enhance immune cell activity to kill the cancer cells; however, this does not result in actual activation of the immune system because of the inhibition signal by checkpoint molecules. Consequently, its clinical application remains controversial among clinical researchers in this field. Recently, many clinicians have become involved in the development of immune checkpoint inhibitors, which release the 'brakes' on the immune system, restoring its activity to normal levels. Their use in cancer immunotherapy is now actively promoted by both companies and academics worldwide. The journal Science selected cancer immunotherapy as its Breakthrough of the Year in 2013, and $\mathrm{Na}$ ture featured the use of immune checkpoint blockade in cancer as a sensational paradigm shift in cancer therapy. Various industry/academia collaborations are ongoing, with the field developing at an amazing speed. Cancer immunotherapy has been described as the beginning of new cancer therapy' [3]; it has also been said that 'cancer immunotherapy comes of age' [4].
Prof. Masatoshi Kudo

Department of Gastroenterology and Hepatology Kindai University Faculty of Medicine

377-2 Ohno-Higashi, Osaka-Sayama, Osaka 589-8511 (Japan)

E-Mail m-kudo@med.kindai.ac.jp 
The first protein identified as an immune checkpoint molecule was programmed cell death 1 (PD-1), which was discovered by Prof. Tasuku Honjo (Kyoto University) in 1992 [5]. Subsequent reports described its involvement in immune regulation and its function as a receptor that 'puts the brakes' on immune responses. In 2000, the PD-1 ligands PD-L1 and PD-L2 were identified by a collaborative project between Prof. Honjo's group at Kyoto University and a group at Harvard University [6, 7]. In 2002, Iwai et al. [8] blocked the interaction between PD-1 and its ligands in a mouse model and found that the resulting increase in the strength of the immune response led to a marked increase in anticancer activity. Based on these findings, Ono Pharmaceutical Co., Ltd. (Japan) and Medarex (later acquired by Bristol-Myers Squibb; both based in the USA) successfully created the humanized anti-PD-1 antibody, nivolumab, in 2005, and clinical trials in humans were initiated in the USA in 2006. Bristol-Myers Squibb and Ono Pharmaceutical Co., Ltd. collaborated and jointly conducted a clinical study in 2009. Nivolumab was first approved for use as a treatment for melanoma in Japan in 2014. Nivolumab is currently approved for the treatment of melanomas, non-small-cell lung cancer, and kidney cancer in the USA. In Japan, it was approved for the treatment of nonsmall-cell lung cancer in 2015 and for kidney cancer in 2016. In addition to nivolumab, pembrolizumab (an anti-PD-1 antibody developed by Merck) is now an approved agent for the treatment of melanoma and nonsmall-cell lung cancer in the USA.

A series of clinical trials are currently examining these two anti-PD-1 antibodies for the treatment of head and neck cancer, breast cancer, Hodgkin's lymphoma, hepatocellular carcinoma (HCC), and bladder cancer, and favorable outcomes were reported at the annual meetings of the American Society of Clinical Oncology (ASCO) and the European Society of Medical Oncology in 2016. These results suggest that antibodies against PD-1 and its ligand PD-L1 will soon be approved for the treatment of many types of cancer.

In 1995, James Allison at the University of Texas MD Anderson Cancer Center found that a different immune checkpoint molecule, cytotoxic T-lymphocyte-associated protein 4 (CTLA-4), acts as a regulator of immune cells [9]. In 1996, he demonstrated tumor regression in mice treated with antibodies that inhibit CTLA-4 function [10]. An antibody against this molecule, ipilimumab, was subsequently developed by Bristol-Myers Squibb and was approved as an anti-melanoma agent in the USA in March 2011, in Europe in July 2011 [11], and in Japan in 2015.

Immune Checkpoint Inhibitors for

Hepatocellular Carcinoma
Clinical trials of monotherapy or combination therapy using one or multiple antibodies against PD-1, PD-L1, or CTLA-4 for the treatment of HCC are currently ongoing, reflecting the rapid progress in this field. This review outlines the basics of immune checkpoint inhibitors and the current status of clinical trials.

\section{Theoretical Mechanism of Antitumor Immunity}

When cells become cancerous, major histocompatibility complex (MHC) molecules on antigen-presenting cells (APCs) recognize tumor-associated antigens. The APCs then migrate to lymph nodes where they present antigens to $\mathrm{T}$ cell receptors expressed on immature $\mathrm{T}$ cells. However, antigen stimulation alone is insufficient for activation of immature T cells; an additional co-stimulatory signal is required. Upon this second signal, namely, binding of CD28 on T cells to CD80/B7-1 or CD86/ B7-2 on APCs, CD8 T cells become activated (priming phase) (fig. 1,2). These activated $\mathrm{T}$ cells then migrate to the tumor site via the bloodstream and recognize tumor antigens presented by MHC molecules on tumor cells, triggering an attack on the tumor cells via perforin and granzymes (effector phase) (fig. 1,2). This process is known as the cancer-immunity cycle (fig. 1) [12].

The effect of a T cell attack cells does not last long. To increase antitumor immunity, several conventional approaches for boosting immune responses, such as therapy with peptides, dendritic cells, cytokines, and lymphokine-activated killer cells, have been investigated. However, at the time these strategies were developed, the brake function in immunity (i.e., immune tolerance or escape) was not fully understood. Therefore, the therapeutic effect of these immune-stimulating agents remained insufficient, which led researchers to question whether these approaches were clinically applicable. In fact, since the brake and the accelerator can be stimulated simultaneously in the immune system, the effects of immune activation are limited. There are two main mechanisms for cancer immune escape: one that occurs in the lymph nodes and anther at the tumor site.

\section{Cancer Immune Escape}

\section{The CTLA-4 Pathway}

The CTLA-4 pathway functions solely within the lymph nodes and regulates the proliferation of activated lymphocytes. CTLA- 4 is expressed constitutively on reg- 
Fig. 1. The cancer-immunity cycle. Cited from Chen and Mellman [12].
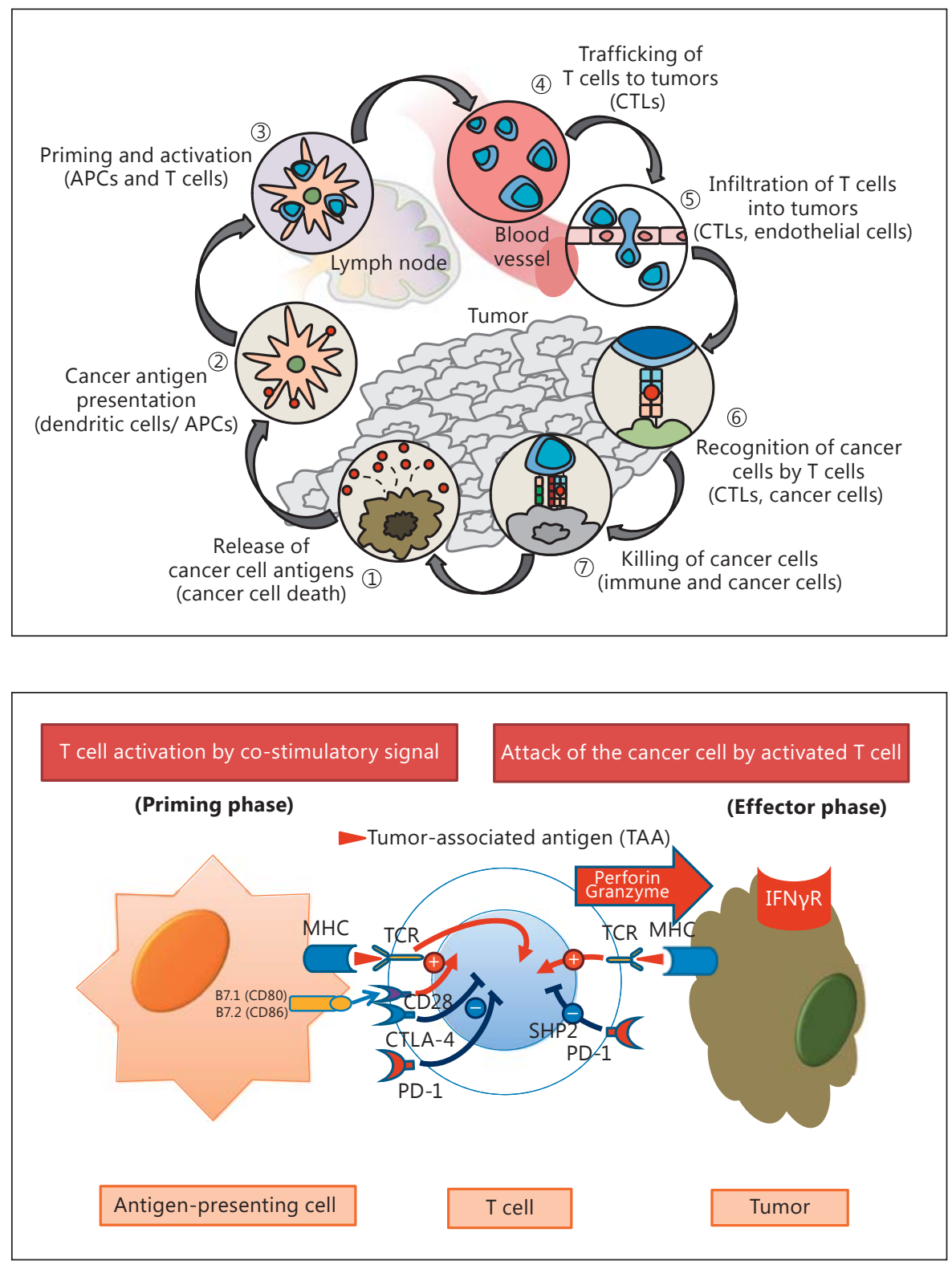

Fig. 2. Cancer attack by activated $\mathrm{T}$ cells. Presentation of tumor-associated antigen by the major histocompatibility complex (MHC) expressed by the antigen-presenting cell leads to the release of an activating signal in combination with a co-stimulatory signal via the B7-CD28 pathway, resulting in activation of $\mathrm{T}$ cells in the lymph node. Subsequently, in the cancer microenvironment, activated $\mathrm{T}$ cells attack the tumor by releasing perforin or granzymes. ulatory T cells (Tregs) and transiently on a broad range of $\mathrm{T}$ cells at the early activation stage (24-48 h). B7-1 and B7-2 (the molecules mediating the second stimulatory signal mentioned above) also bind to CTLA-4, and their affinity for CTLA-4 is 10 times as strong as it is for CD28. Therefore, these ligands favor binding to CTLA- 4 over binding to CD28, and activation of $\mathrm{T}$ cell does not occur. CTLA- 4 prevents excessive $\mathrm{T}$ cell immune responses by halting physiologically unnecessary $\mathrm{T}$ cell activity. However, in anticancer immunity, this acts as a brake on the activation and proliferation of valuable activated $\mathrm{T}$ cells that recognize cancer antigens (fig. 3).
Therapy with an anti-CTLA-4 antibody aims to release this brake on $\mathrm{T}$ cell activation in the lymph nodes. The use of a CTLA-4 antibody for cancer treatment was first suggested in 1996 by Allison [10], who worked on a mouse model wherein an inhibitory antibody against CTLA-4 eliminated tumors. Given that CTLA-4 is most strongly expressed on Tregs, the mechanism of action of antiCTLA- 4 antibodies may involve inhibition of Treg activity. Two antibodies against CTLA-4, ipilimumab and tremelimumab, are currently being actively investigated in clinical trials (table 1). 
Fig. 3. Cancer immune escape by the immune checkpoint molecules PD-1, PD-L1, and CTLA-4. Immune escape is induced in cancer via the PD-1/PD-L1 axis. T cell activation is also suppressed by the B-7/ CTLA-4 axis.

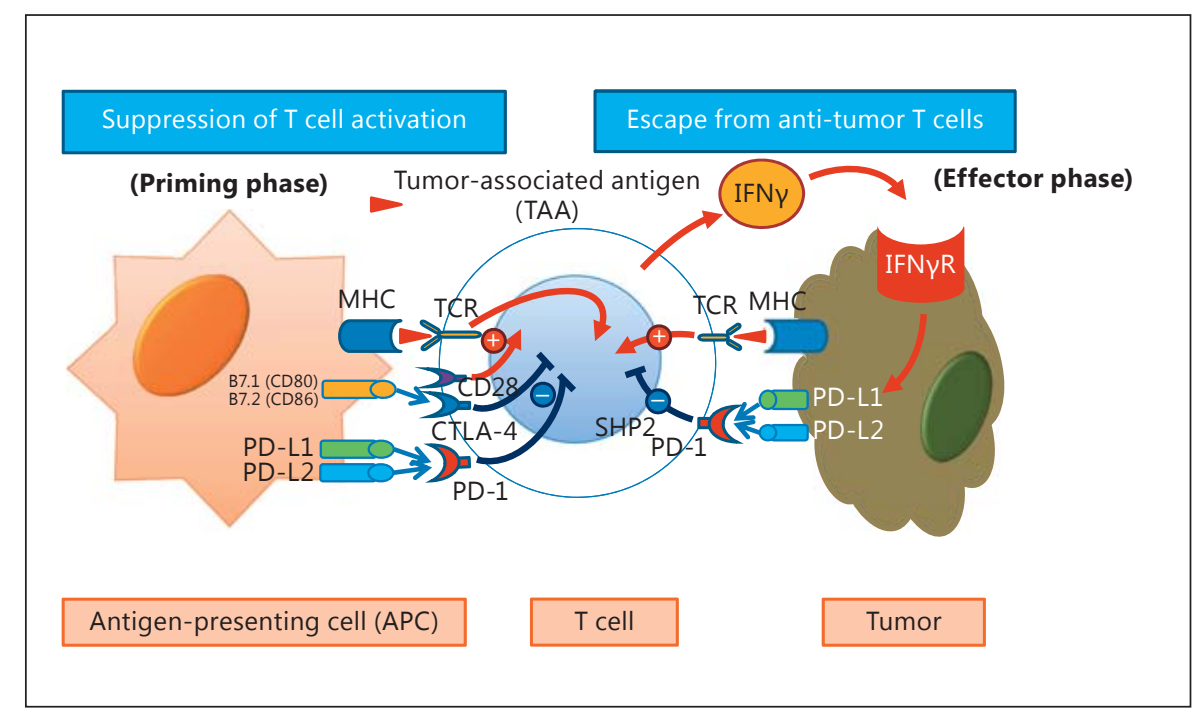

Table 1. Immune checkpoint inhibitors

\begin{tabular}{|c|c|c|c|c|c|c|}
\hline Target cell & $\begin{array}{l}\text { Target } \\
\text { molecule }\end{array}$ & $\begin{array}{l}\text { Development } \\
\text { code }\end{array}$ & Drug name & $\begin{array}{l}\text { Commercial } \\
\text { name }\end{array}$ & Antibody & Company \\
\hline \multirow[t]{2}{*}{ T lymphocyte } & PD-1 & $\begin{array}{l}\text { BMS-36558 } \\
\text { ONO-4538 }\end{array}$ & nivolumab & Optivo & $\begin{array}{l}\text { fully human IgG4 } \\
\text { antibody }\end{array}$ & Ono/BMS \\
\hline & $\mathrm{PD}-1$ & MK-4375 & pembrolizumab & Keytruda & $\begin{array}{l}\text { humanized IgG4 } \\
\text { antibody }\end{array}$ & Merck \\
\hline \multirow{2}{*}{ Tumor cell } & PD-L1 & MEDI4736 & durvalumab & not approved & $\begin{array}{l}\text { humanized IgG1 } \\
\text { antibody }\end{array}$ & AstraZeneca \\
\hline & PD-L1 & MSB-0010718C & avelumab & not approved & $\begin{array}{l}\text { humanized IgG1 } \\
\text { antibody }\end{array}$ & Merck Serono \\
\hline
\end{tabular}

Ono $=$ Ono Pharmaceutical Co., Ltd.; BMS = Bristol-Myers Squibb .

\section{The PD-1/PD-L1 Pathway}

PD-1 is an immune co-inhibitory receptor expressed on T cells, B cells, NK cells, and myeloid cells. On T cells, $\mathrm{PD}-1$ suppresses antigen-specific $\mathrm{T}$ cell activation through interactions with its ligands PD-L1 and PD-L2. PD-L1 is expressed on dendritic cells and in a broad range of tissues, including blood vessels, the myocardium, lung, and placenta, while PD-L2 expression is restricted to dendrit- ic cells. PD-1 is rarely expressed on peripheral blood lymphocytes in normal mice and healthy humans; it is expressed selectively on $\mathrm{T}$ cells at the late activation stage in association with infection or an immune response (e.g., inflammation). Expression of PD-1 is particularly strong in effector $\mathrm{T}$ cells in peripheral tissues.

In contrast to PD-1, PD-L1 is constitutively expressed in normal peripheral tissues and on most immune cells 
Fig. 4. Cancer attack by immune checkpoint blockade with anti-PD-1, anti-PDL1, or anti-CTLA-4 antibody. T cell activation and effective cancer attack are restored by anti-CTLA-4, anti-PD-1, and anti-PDL1 antibodies.

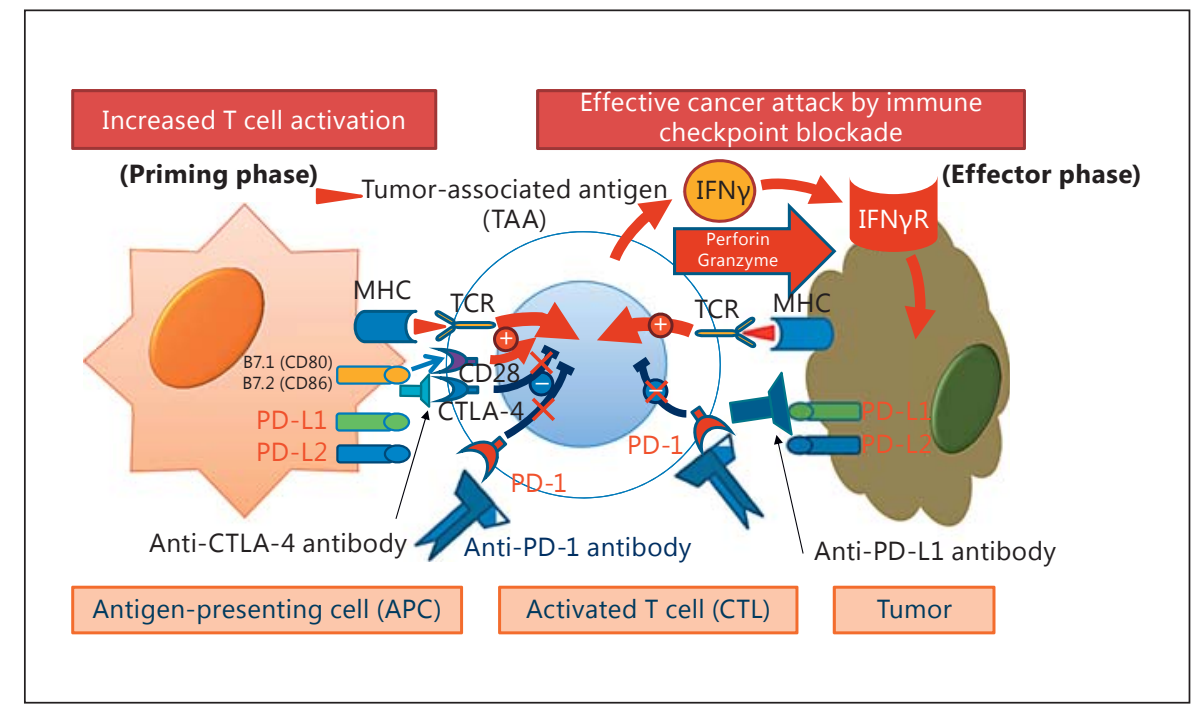

during the initiation of the immune response. The majority of cancer cells also express this molecule through the mechanism described below. Conversely, PD-L2 expression is selective and limited to APCs, suggesting its involvement in T cell activation in the lymph node. Taken together, these observations explain why antibodies against PD-1 and PD-L1 are equally effective while PDL2 plays a limited role in anticancer immunity.

When $\mathrm{T}$ cell receptors on activated $\mathrm{T}$ cells recognize cancer antigens presented by MHC molecules on cancer cells, perforin and granzymes are released to attack the cancer cells. At the same time, interferon- $\gamma$ and other cytokines are released by the activated $\mathrm{T}$ cells. In response to these cytokines, cancer cells upregulate PD-L1, which binds to PD-1 on the T cells, thereby weakening the T cell attack (i.e., resulting in immune escape or immune tolerance) (fig. 3).

Administration of anti-PD-1 antibodies releases this brake mechanism and allows $\mathrm{T}$ cells to remain active despite the inhibitory molecules expressed by the tumor (fig. 4). In other words, unlike conventional chemotherapy and molecular targeted therapy, this approach takes advantage of the immune system's natural antitumor response and aims to amplify and prolong it [13-24]. Antibodies to PD-L1 have an effect similar to that of PD-1 antibodies. PD-L1 overexpression is a marker of tumor aggressiveness [25]. PD-L1 is also being explored as a potential biomarker to predict the efficacy of anti-PD-1 therapy. Patients with high PD-L1 expression may be more likely to respond well to anti-PD-1 therapy.

\section{Results from Previous Studies with Anti-PD-1 Antibodies}

Approved immune checkpoint inhibitors include nivolumab and pembrolizumab (anti-PD-1 antibodies) as well as ipilimumab (an anti-CTLA-4 antibody). Other agents under development include tremelimumab (an anti-CTLA-4 antibody) and durvalumab, avelumab, and atezolizumab (anti-PD-L1 antibodies) (table 1).

A study of pembrolizumab demonstrated the marked effect of an anti-PD-1 antibody when used to treat DNA mismatch repair (MMR)-deficient colorectal cancer and other types of solid tumor [21].

Clinical trials are currently underway to evaluate immune checkpoint inhibitors for the treatment of various types of cancer, including esophageal cancer, gastric cancer, MMR-deficient colorectal cancer, head and neck cancer, breast cancer, small-cell lung cancer, Hodgkin's lymphoma, ovarian cancer, and bladder cancer.

The response rates to anti-PD-1 monotherapy are 10$30 \%$ overall, but response rates are much higher in extremely immunogenic tumors such as malignant melanoma and Hodgkin's disease. Disease control rates, which include patients with stable disease (SD), are around $70 \%$ overall, suggesting that approximately $30 \%$ of patients do not respond to anti-PD-1 antibody monotherapy. Although the causes of nonresponsiveness remain unclear, one possibility is that there may be additional molecules involved in immune escape other than PD-1, PD-L1/2, and CTLA-4. This question might be answered by the development of antibodies that block oth- 
Fig. 5. Immune co-regulatory signals related to the immune checkpoint. There are two types of co-regulatory signals: inhibitory signals and stimulatory signals.

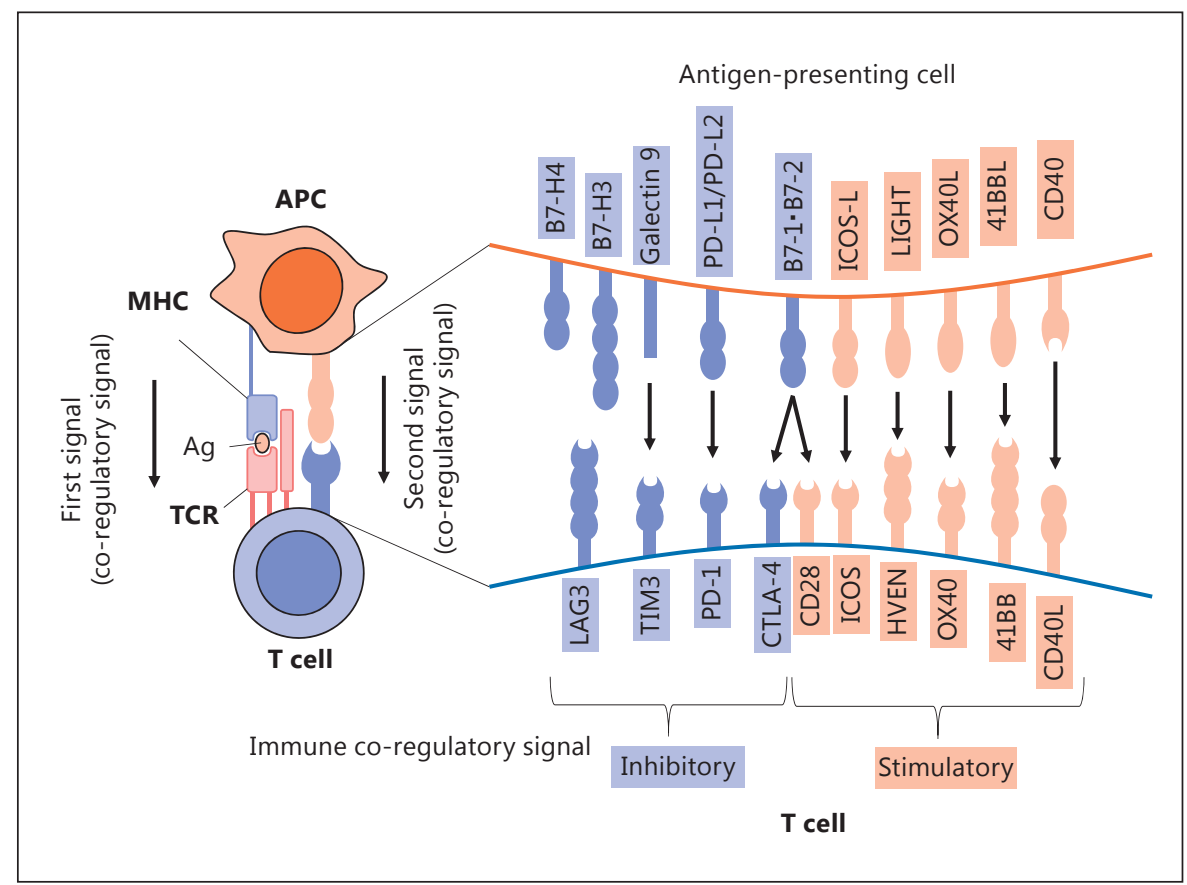

Table 2. Investigator-assessed best overall response (RECIST v1.1)

\begin{tabular}{|c|c|c|c|c|c|}
\hline & $\begin{array}{l}\text { Uninfected: sorafenib-naive } \\
\text { or -intolerant }(\mathrm{n}=54)\end{array}$ & $\begin{array}{l}\text { Uninfected: sorafenib } \\
\text { progressors }(n=58)\end{array}$ & $\begin{array}{l}\mathrm{HCV} \\
(\mathrm{n}=51)\end{array}$ & $\begin{array}{l}\mathrm{HBV} \\
(\mathrm{n}=51)\end{array}$ & $\begin{array}{l}\text { Total } \\
(\mathrm{n}=214)\end{array}$ \\
\hline Objective response & $11(20 \%)$ & $11(19 \%)$ & $7(14 \%)$ & $6(12 \%)$ & $35(16 \%)$ \\
\hline Partial response & $11(20 \%)$ & $9(16 \%)$ & $7(14 \%)$ & $6(12 \%)$ & $33(15 \%)$ \\
\hline Stable disease & $32(59 \%)$ & $27(47 \%)$ & $29(57 \%)$ & $23(45 \%)$ & $111(52 \%)$ \\
\hline Progressive disease & $11(20 \%)$ & $18(31 \%)$ & $12(24 \%)$ & $22(43 \%)$ & $63(29 \%)$ \\
\hline
\end{tabular}

CheckMate 040 Dose Expansion Cohort $(\mathrm{n}=214)$. Cited from Sangro et al. [42].

er inhibitory immune checkpoint molecules such as TIM3 or LAG3, or by the development of agonists of activation signals (fig. 5).

\section{Combination Immunotherapy}

A different approach to anticancer immunotherapy is combination therapy to simultaneously block the suppressive signals of both PD-1 and a CTLA-4. The objective of this strategy is to achieve a stronger therapeutic effect than what can be achieved with single-agent therapy. The advantages of such an approach have been shown for the treatment of malignant melanoma [26]. The rationale of this strategy is based on the idea that if CD8-positive T cells do not exist in cancer tissues, blockade of the PD-1/PD-L1 pathway cannot be expected to be efficacious. Therefore, blocking CTLA-4 may be an effective strategy to increase the number of activated CD8-positive T cells that infiltrate the tumor tissue. Indeed, a combination trial of an anti-CTLA-4 antibody and a PD-1/PD-L1 antibody for the treatment of HCC is in the early stages (table 2). A three-arm phase I/II trial is currently investigating the combination of nivolumab (anti-PD-1) and ipilimumab (anti-CTLA-4) at varying doses and intervals. Another three-arm trial 
is currently comparing the efficacy and safety of combination therapy with durvalumab (anti-PD-L1) and tremelimumab (anti-CTLA-4) with the corresponding monotherapies. The results of these trials are eagerly awaited.

A different approach is pretreatment of HCC with transcatheter arterial chemoembolization, radiofrequency ablation, or radiation to induce inflammation or thermocoagulation, thereby creating conditions that favor tumor neoantigen generation prior to the initiation of immunotherapy. This type of pretreatment is expected to be beneficial when cancer antigen recognition has not been established due to a lack of neoantigen release. An investigator-initiated clinical trial of this approach was recently initiated in stage III and IV HCC patients [27].

\section{Biomarkers in Immune Checkpoint Blockade}

In 2010, Brahmer et al. [28] showed that PD-1 pathway inhibitors have a stronger therapeutic effect in patients with high levels of PD-L1 expression. The level of PD-L1 expression in tumors can vary greatly throughout the course of treatment $[14,29]$. Furthermore, differences in the timing and method of specimen collection (biopsy or surgical specimens), the preparation of the specimen (paraffin-embedded or frozen), the evaluation method (immunohistostaining, quantitative PCR, or Western blotting), and the cutoff values used also greatly influence the apparent $\mathrm{PD}-\mathrm{L} 1$ expression.

Only $10-30 \%$ of patients respond to anti-PD-1/PD-L1 therapy, and even when patients with SD are included, the drug is effective in only $70 \%$ of them; the remaining $30 \%$ do not respond at all to immune checkpoint inhibitors. In practice, although disease progression is sometimes observed immediately after initiation of therapy, treatment must be continued in nonresponders because of the possibility of pseudoprogression. Some responders also require long-term administration of the therapy. Therefore, the identification of biomarkers to predict response is urgently needed, both from the perspective of the effective use of medical resources and to prevent adverse effects caused by unnecessary treatment. There as several highly promising candidate predictors of a therapeutic effect: PD-L1 expression in tumor tissue, the number of tumorinfiltrating lymphocytes, and the presence of CD8-positive $\mathrm{T}$ cells in the cancer microenvironment. Kupffer phase findings in Sonazoid contrast-enhanced ultrasound are another possible imaging biomarker that may predict the effect of anti-PD-1 therapy [30].
The possibility of MMR deficiency serving as a biomarker for the therapeutic effect of pembrolizumab, an antiPD-1 antibody, was demonstrated in a clinical study examining three cohorts: 25 patients with MMR-deficient colorectal cancer, 25 patients with MMR-normal colorectal cancer, and 21 patients with MMR-deficient cancers other than colorectal cancer [21]. The response rate and disease control rate were 62 and 92\%, respectively, in MMR-deficient colorectal cancer patients, and 60 and $70 \%$, respectively, in patients with MMR-deficient noncolorectal cancer, while both rates were extremely low ( 0 and $16 \%$, respectively) in MMR-normal colorectal patients.

Rapid advances in high-throughput analysis techniques should enable the identification and verification of more effective biomarkers in cancer immunotherapy. An example of such high-throughput analysis is mutanome analysis, where next-generation sequencing is globally performed in cancer genomes to search for biomarkers. Another example is immunome analysis, which employs $\mathrm{T}$ cell repertoire analysis, microarray analysis, and protein analysis. The results of these studies are leading to the identification of biomarkers for various cancers.

\section{Adverse Events}

The toxicities associated with immune checkpoint inhibitors are milder than those of cytotoxic anticancer agents and molecular targeted agents. However, immune checkpoint inhibition can induce adverse events related to autoimmunity such as hyperthyroidism, hypothyroidism, type 1 diabetes mellitus, myasthenia gravis, rheumatoid arthritis, or Addison's disease. Many of these adverse events can be controlled by withdrawal of immune checkpoint inhibitors and initiation of steroid therapy. Immune-related adverse events are least frequent in patients treated with anti-PD-L1 antibodies and most frequent in patients treated with anti-CTLA-4 antibodies (fig. 4) [31]. Other adverse events include dry mouth, hepatitis, dermopathy, pancreatitis, pneumonitis, adrenal insufficiency, enteritis, arthritis, and uveitis.

\section{Results of Clinical Trials in HCC}

Long-awaited results from an interim analysis of a phase I/II trial of nivolumab (anti-PD-1) in patients with advanced HCC (CA209-040 trial) were presented at the 2015 ASCO meeting held in Chicago [32]. A dose escalation study showed that nivolumab was safely adminis- 
Table 3. Overall survival rates (percentage with $95 \%$ confidence interval in parentheses ${ }^{1}$ )

\begin{tabular}{llllll}
\hline & $\begin{array}{l}\text { Uninfected: sorafenib-naive } \\
\text { or -intolerant }(\mathrm{n}=54)\end{array}$ & $\begin{array}{l}\text { Uninfected: sorafenib } \\
\text { progressors }(\mathrm{n}=58)\end{array}$ & $\begin{array}{l}\mathrm{HCV} \\
(\mathrm{n}=51)\end{array}$ & $\begin{array}{l}\text { HBV } \\
(\mathrm{n}=51)\end{array}$ & $\begin{array}{l}\text { Total } \\
(\mathrm{n}=214)\end{array}$ \\
\hline $\begin{array}{l}6 \text { months } \\
9 \text { months }\end{array}$ & \begin{tabular}{l}
$89.8(77.1-95.6)$ \\
\hline
\end{tabular} & $\begin{array}{l}75.6(61.5-85.2) \\
\text { not calculated }\end{array}$ & $\begin{array}{l}82.1(61.3-92.4) \\
\text { not calculated }\end{array}$ & $\begin{array}{l}83.3(67.6-91.8) \\
\text { not calculated }\end{array}$ & $\begin{array}{l}82.5(75.8-87.5) \\
70.8(56.6-81.1)\end{array}$ \\
\hline
\end{tabular}

${ }^{1}$ Estimated using the Kaplan-Meier method. CheckMate 040 Dose Expansion Cohort $(\mathrm{n}=214)$. Cited from Sangro et al. [42].

tered up to a dose of $3 \mathrm{ml} / \mathrm{kg}$ in hepatitis C virus (HCV)infected, hepatitis B virus (HBV)-infected, and uninfected individuals, and confirmed the safety of nivolumab at $10 \mathrm{ml} / \mathrm{kg}$ in the uninfected group. At the same time, the efficacy of nivolumab in a range from 0.1 to $3 \mathrm{ml} / \mathrm{kg}$ was also reported. Among a total of 47 subjects, $33(70 \%)$ had extrahepatic metastasis, 6 (13\%) had vascular invasion, and $32(68 \%)$ had a history of sorafenib therapy, suggesting that these patients had relatively advanced liver cancers. The report (interim analysis date: March 12, 2015) indicated that 17 patients remained on nivolumab therapy, while therapy was completed or discontinued in 30 patients because of disease progression in 26 patients, an adverse event in 2 patients (elevated bilirubin in one and an unrelated event in the other), and a complete response (CR) in 2 patients. The only CTCAE grade IV adverse event was elevation of lipase levels. Grade III increases in aspartate amino transferase levels were seen in 5 (11\%) patients, and increases in alanine amino transferase levels were seen in 4 (9\%) patients. Autoimmune disease and hepatic dysfunction, which were the adverse events of initial concern, were not observed.

The response rate was $19 \%$ (8 patients) and the CR rate was $5 \%$ (2 patients). The disease control rate (including SD cases) was $67 \%$ (28 patients), while progressive disease (PD) occurred in $33 \%$ of patients (14 cases). Waterfall plots revealed a tumor size reduction in all cohorts (HBV patients, HCV patients, and uninfected patients). The responders showed a notable, durable response. Two patients achieved CR at $\leq 3$ months and remained in remission for 18 months. A sustained response was seen in all partial response (PR) and SD cases, and reversion to PD due to acquisition of resistance was not observed in any case. Taken together, these results confirmed that treatment with the anti-PD-1 antibody nivolumab produced a durable response in patients with HCC, as reported in patients with other types of cancer. This is the most unique and notable characteristic of immune checkpoint inhibitors, especially considering that 2 patients achieved

Immune Checkpoint Inhibitors for Hepatocellular Carcinoma
CR within 3 months and maintained this response for longer than 18 months despite the termination of nivolumab therapy several months after $\mathrm{CR}$ was achieved.

In most patients who achieved CR/PR, the response was evident within 3 months. In clinical cases presented at ASCO 2015, a large number of multiple HCCs disappeared after 6 weeks of therapy, and the alpha-fetoprotein level in 1 case dropped from 21,000 to $283 \mathrm{ng} / \mathrm{ml}$. The overall survival rate at 12 months was $62 \%$. Furthermore, a continuous reduction in tumor size (from approximately 10 to $2 \mathrm{~cm}$ ) was observed in a patient after 48 weeks. Taken together, these outcomes are very promising, especially considering the poor tumor-related patient characteristics in this patient cohort.

In summary, monotherapy with nivolumab, an antiPD-1 antibody, had a favorable safety profile in patients with HCC (comparable to that seen in patients with other types of cancer); it can be used safely in patients with $\mathrm{HBV}$ and $\mathrm{HCV}$ infection, and its high response rate was groundbreaking compared to the rates achievable with other types of immunotherapy. Durable responses were seen at all dose levels regardless of etiology ( $\mathrm{HBV}, \mathrm{HCV}$, and uninfected cohorts).

Since then, a fixed dose of $3 \mathrm{mg} / \mathrm{kg}$ of nivolumab was planned in expansion cohorts of 50 uninfected patients with PD after sorafenib treatment failure, 50 uninfected patients who were sorafenib-naive or -intolerant, 50 $\mathrm{HCV}$-infected patients, and $50 \mathrm{HBV}$-infected patients. Outcomes of the fixed dose trial and the final results of the dose escalation study were reported at the 2016 ASCO meeting.

\section{Ongoing Clinical Trials}

According to the outcomes reported at the 2016 ASCO meeting, 35 (16\%) of the 214 patients in the dose expansion cohort achieved a response, including $2(1 \%)$ who achieved CR and 33 (15\%) who achieved PR (table 2). 
Table 4. Baseline patient characteristics and prior treatment history

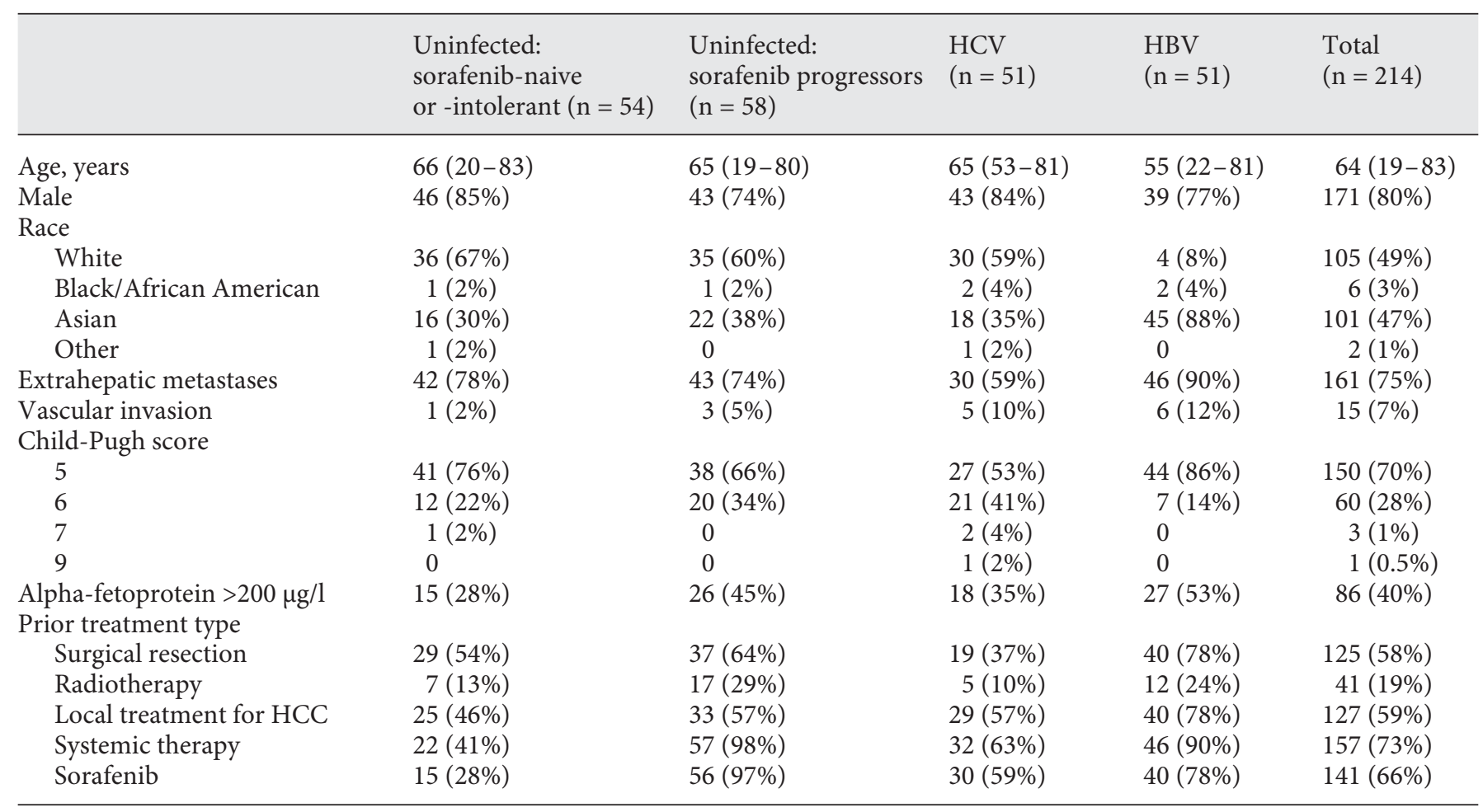

Figures are given as mean (range) or n (\%). CheckMate 040 Dose Expansion Cohort $(\mathrm{n}=214)$. Cited from Sangro et al. [42].

Furthermore, 111 patients (52\%) had SD and $63(29 \%)$ had PD (table 3).

The response rates in the cohorts of uninfected patients who were sorafenib-naive or -intolerant, uninfected patients with PD after sorafenib treatment failure, $\mathrm{HCV}$-infected patients, and $\mathrm{HBV}$-infected patients were $20,19,14$, and $12 \%$, respectively (table 3 ). Nine-month survival was favorable (70\%) (table 4). Considering that a high proportion $(66 \%)$ progressed on sorafenib treatment (table 5), these outcomes appear to be extremely good. The frequency of adverse events was also extremely low. The most concerning treatment-related adverse event was hepatic dysfunction; however, only $9(4 \%)$ and $6(3 \%)$ patients showed grade 3-4 increases in aspartate amino transferase and alanine amino transferase levels, respectively (table 6). These figures were comparable to those reported in nivolumab-treated patients with other types of cancer. Severe hepatic dysfunction related to nivolumab therapy in patients with viral hepatitis, which was an original concern, was not observed in any patient.

Additional analysis of the dose escalation cohort (48 patients) showed that $3(6 \%)$ and $4(8 \%)$ patients achieved CR and PR, respectively, while $24(50 \%)$ and 15 (13\%) had SD and $\mathrm{PD}$, respectively. The response rate was $13 \%$ in the noninfected group and $30 \%$ and $7 \%$ in the HCV- and $\mathrm{HBV}$-infected groups, respectively (table 5). In this CA209040 phase I/II trial, a dose escalation cohort (cohort 2), a cohort for randomized comparison against sorafenib (cohort 3), and a combination therapy cohort (with an antiCTLA-4 antibody, ipilimumab) (cohort 4), in addition to the dose escalation cohort (cohort 1), were tested and registered. Furthermore, based on the tolerability and low frequency of hepatic dysfunction observed in patients with liver cirrhosis, a trial of nivolumab in patients with ChildPugh B HCC (cohort 5) was initiated (table 2).

Following these trials, a phase III trial directly comparing nivolumab with sorafenib was initiated, as was a clinical trial investigating the efficacy of second-line pembrolizumab in patients who did not respond to sorafenib. Monotherapy with an anti-PD-1 antibody (nivolumab or pembrolizumab) or combination therapy is expected to be successful. A clinical trial examining the use of an antiCTLA-4 antibody in HCC has also been conducted, but the results, reported in the Journal of Hepatology in 2013, indicated more adverse events than those caused by antiPD-1 antibodies [33]. 
Table 5. Treatment-related adverse events (TRAEs)

\begin{tabular}{|c|c|c|c|c|c|c|c|c|}
\hline & \multicolumn{2}{|c|}{ Uninfected $(\mathrm{n}=112)$} & \multicolumn{2}{|c|}{$\mathrm{HCV}(\mathrm{n}=51)$} & \multicolumn{2}{|c|}{$\operatorname{HBV}(\mathrm{n}=51)$} & \multicolumn{2}{|c|}{ Total $(\mathrm{n}=214)$} \\
\hline & any grade & grade $3-4$ & any grade & grade $3-4$ & any grade & grade $3-4$ & any grade & grade $3-4$ \\
\hline Patients with any TRAE & $72(64 \%)$ & $21(19 \%)$ & $37(73 \%)$ & $15(29 \%)$ & $30(59 \%)$ & $3(6 \%)$ & $139(65 \%)$ & $39(18 \%)$ \\
\hline \multicolumn{9}{|c|}{ Symptomatic TRAEs reported in $>4 \%$ of all patients } \\
\hline Fatigue & $31(28 \%)$ & $2(2 \%)$ & $7(14 \%)$ & 0 & $7(14 \%)$ & 0 & $45(21 \%)$ & $2(1 \%)$ \\
\hline Pruritus & $11(10 \%)$ & 0 & $11(22 \%)$ & 0 & $11(22 \%)$ & 0 & $33(15 \%)$ & 0 \\
\hline Rash & $12(11 \%)$ & $1(1 \%)$ & $8(16 \%)$ & 0 & $6(12 \%)$ & 0 & $26(12 \%)$ & $1(0.5 \%)$ \\
\hline Diarrhea & $16(14 \%)$ & $2(2 \%)$ & $3(6 \%)$ & 0 & $1(2 \%)$ & $1(2 \%)$ & $20(9 \%)$ & $3(1 \%)$ \\
\hline Nausea & $8(7 \%)$ & 0 & $6(12 \%)$ & 0 & 0 & 0 & $14(7 \%)$ & 0 \\
\hline Decreased appetite & $5(5 \%)$ & 0 & $2(4 \%)$ & 0 & $3(6 \%)$ & 0 & $10(5 \%)$ & 0 \\
\hline Dry mouth & $5(4 \%)$ & 0 & $1(2 \%)$ & 0 & $2(4 \%)$ & 0 & $8(4 \%)$ & 0 \\
\hline \multicolumn{9}{|c|}{ Laboratory-value TRAEs reported in $>4 \%$ of all patients } \\
\hline ALT increased & $6(5 \%)$ & $2(2 \%)$ & $7(14 \%)$ & $4(8 \%)$ & $2(4 \%)$ & 0 & $15(7 \%)$ & $6(3 \%)$ \\
\hline AST increased & $7(6 \%)$ & $3(3 \%)$ & $6(12 \%)$ & $6(12 \%)$ & 0 & 0 & $13(6 \%)$ & $9(4 \%)$ \\
\hline Platelet count decreased & $4(4 \%)$ & $1(1 \%)$ & $3(6 \%)$ & $2(4 \%)$ & $5(10 \%)$ & $1(2 \%)$ & $8(4 \%)$ & $3(1 \%)$ \\
\hline Anemia & $2(2 \%)$ & 0 & $3(6 \%)$ & $1(2 \%)$ & $3(6 \%)$ & 0 & $8(4 \%)$ & $1(0.5 \%)$ \\
\hline
\end{tabular}

CheckMate 040 dose expansion cohort $(n=214)$. Cited from Sangro et al. [42]. ALT = Alanine amino transferase; AST = aspartate amino transferase.

Table 6. Current clinical trials of immune checkpoint inhibitors for HCC

\begin{tabular}{|c|c|c|c|c|c|c|c|c|c|}
\hline Drug & Trial name & ClinicalTrials.gov & Company & Phase & $\mathrm{n}$ & $\begin{array}{l}\text { Line of } \\
\text { therapy }\end{array}$ & Design & Endpoint & Status \\
\hline \multicolumn{10}{|l|}{ Nivolumab } \\
\hline Nivolumab (PD-1 Ab) & CheckMate 040 & NCT01658878 & $\mathrm{BMS} / \mathrm{ONO}$ & $\mathrm{I} / \mathrm{II}$ & 42 & $1 \mathrm{~L} / 2 \mathrm{~L}$ & cohort 1: dose escalation & DLT/MTD & completed \\
\hline Nivolumab (PD-1 Ab) & CheckMate 040 & NCT01658878 & BMS/ONO & $\mathrm{I} / \mathrm{II}$ & 214 & $1 \mathrm{~L} / 2 \mathrm{~L}$ & cohort 2: dose expansion & ORR & completed \\
\hline Nivolumab (PD-1 Ab) & CheckMate 040 & NCT01658878 & $\mathrm{BMS} / \mathrm{ONO}$ & $\mathrm{I} / \mathrm{II}$ & 200 & $1 \mathrm{~L}$ & $\begin{array}{l}\text { cohort 3: nivolumab vs. } \\
\text { sorafenib }\end{array}$ & ORR & completed \\
\hline $\begin{array}{l}\text { Nivolumab (PD-1 Ab)/ } \\
\text { ipilimumab (CTLA-4 Ab) }\end{array}$ & CheckMate 040 & NCT01658878 & BMS/ONO & $\mathrm{I} / \mathrm{II}$ & 120 & $2 \mathrm{~L}$ & $\begin{array}{l}\text { cohort 4: nivolumab + } \\
\text { ipilimumab }\end{array}$ & $\begin{array}{l}\text { safety/ } \\
\text { tolerability }\end{array}$ & completed \\
\hline Nivolumab (PD-1 Ab) & CheckMate 040 & NCT01658878 & BMS/ONO & $\mathrm{I} / \mathrm{II}$ & - & $1 \mathrm{~L} / 2 \mathrm{~L}$ & $\begin{array}{l}\text { cohort 5: nivolumab } \\
\text { (Child B patients) }\end{array}$ & $\begin{array}{l}\text { safety/ } \\
\text { tolerability }\end{array}$ & recruiting \\
\hline Nivolumab (PD-1 Ab) & CheckMate 459 & NCT02576509 & ONO & III & 726 & $1 \mathrm{~L}$ & nivolumab vs. sorafenib & TTP/OS & recruiting \\
\hline \multicolumn{10}{|l|}{ Pembrolizumab } \\
\hline Pembrolizumab (PD-1 Ab) & KEYNOTE-224 & NCT02702414 & MSD & II & 100 & $2 \mathrm{~L}$ & pembrolizumab ( $1 \mathrm{arm})$ & ORR & completed \\
\hline Pembrolizumab (PD-1 Ab) & KETNOTE-240 & NCT02702401 & MSD & III & 408 & $2 \mathrm{~L}$ & pembrolizumab vs. placebo & PFS/OS & recruiting \\
\hline \multicolumn{10}{|l|}{ Durvalumab } \\
\hline $\begin{array}{l}\text { Durvalumab (PD-L1 Ab)/ } \\
\text { tremelimumab (CTLA-4 Ab) }\end{array}$ & - & NCT02519348 & AstraZeneca & II & 144 & $1 \mathrm{~L} / 2 \mathrm{~L}$ & $\begin{array}{l}\text { durvalumab }(\operatorname{arm} A) ; \\
\text { tremelimumab }(\operatorname{arm} B) ; \\
\text { durvalumab + tremelimumab } \\
(\text { arm C) }\end{array}$ & $\begin{array}{l}\text { safety/ } \\
\text { tolerability }\end{array}$ & recruiting \\
\hline
\end{tabular}

BMS = Bristol-Myers Squibb; DLT = dose-limiting toxicity; MTD = maximum tolerated dose; Ono = Ono Pharmaceutical Co., Ltd.; ORR = overall response rate; OS = overall survival; PFS = progression-free survival; TTP = time to progression.

\section{Future Prospects}

The outcomes described above, which were reported at the 2015 and 2016 ASCO meetings, were interim analysis results of phase I/II trials of monotherapy with an anti-PD-1 antibody (nivolumab) in HCC patients. Ni- volumab is approved for the treatment of melanoma, non-small-cell lung cancer, and kidney cancer (in the USA), and similar effects in other types of cancer are expected. HCC is an extremely heterogeneous cancer, does not have a clear driver mutation, and cannot be treated with agents that reduce hepatic functional reserve; there- 
Fig. 6. Treatment strategy using immune checkpoint inhibitors. RFA = Radiofrequency ablation; TACE = transcatheter arterial chemoembolization.

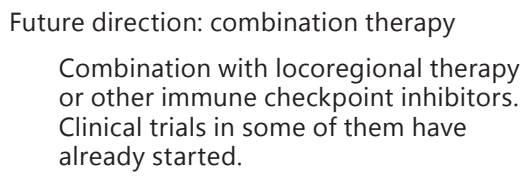

Future direction: combination therapy

Combination with locoregional therapy or other immune checkpoint inhibitors. Clinical trials in some of them have already started.

Immune checkpoint inhibitors (anti-PD-1 antibody, anti-PD-L1 antibody, anti-CTLA-4 antibody)



Other immune checkpoint inhibitors (anti-PD-1, PD-L1, CTLA-4 antibodies) fore, different therapeutic strategies from those used for other types of solid tumors and hematologic malignancies are needed. Based solely on the outcomes of the phase I/II trials, anti-PD-1 antibody therapy seems highly promising, and several pharmaceutical companies have started clinical trials in HCC patients. The outcomes of these studies are eagerly awaited.

There are unmet needs at various stages of HCC treatment, such as neoadjuvants and adjuvants after resection $[34,35]$ and ablation [36-38], combination therapy with transcatheter arterial chemoembolization [39-41], and first- and second-line treatments. Novel antibodies against PD-1 and PD-L1 may be beneficial at these stages. Their combination with other anti-angiogenic agents, locoregional therapy, another checkpoint inhibitor such as an anti-CTLA-4 antibody (ipilimumab or tremelimumab), or with a molecular targeted agent (e.g., sorafenib or lenvatinib) appears promising. Indeed, combination therapy with nivolumab and ipilimumab produces better therapeutic outcomes than the corresponding monotherapies [12].

The development of combination immunotherapy for the treatment of other types of cancer is rapidly advancing. Nivolumab became an FDA-designated breakthrough therapy in September 2014, followed by pembrolizumab. Antibodies against PD-1/PD-L1 and CTLA-4 are expected to be approved for the treatment of additional types of cancer, particularly in the setting of liver cancer, where they are expected to be implemented in the very near future.

Immune checkpoint inhibitors will play a major role in combination with other chemotherapies and locore- gional therapies as treatment strategies against liver cancer, with high hopes for improved therapeutic outcomes (fig. 6). We are in the middle of a paradigm shift, not only for systemic therapy, but also for multimodal therapeutic strategies against liver cancer. There is no doubt that immune checkpoint inhibitors will play a key role.

\section{Conclusion}

Anticancer therapy has progressed through the first and second stages of treatment strategies with cytotoxic agents and molecular targeted agents, respectively. We are now about to enter the third stage with immune checkpoint blockade. Immune checkpoint inhibitorbased strategies will soon become the mainstay of anticancer treatment for liver cancer, and we will continue to watch the rapid advances in the therapeutic use of immune checkpoint inhibitors with great interest.

\section{Disclosure Statement}

The author declares no conflicts of interest regarding the publication of this paper.
60

Oncology 2017;92(suppl 1):50-62 DOI: $10.1159 / 000451016$
Kudo 


\section{References}

1 Hodi FS, O’Day SJ, McDermott DF, Weber RW, Sosman JA, Haanen JB, Gonzalez R, Robert C, Schadendorf D, Hassel JC, Akerley W, van den Eertwegh AJ, Lutzky J, Lorigan P, Vaubel JM, Linette GP, Hogg D, Ottensmeier $\mathrm{CH}$, Lebbe C, Peschel C, Quirt I, Clark JI, Wolchok JD, Weber JS, Tian J, Yellin MJ, Nichol GM, Hoos A, Urba WJ: Improved survival with ipilimumab in patients with metastatic melanoma. N Engl J Med 2010;363:711723.

2 Brahmer JR, Tykodi SS, Chow LQ, Hwu WJ, Topalian SL, Hwu P, Drake CG, Camacho LH, Kauh J, Odunsi K, Pitot HC, Hamid O, Bhatia S, Martins R, Eaton K, Chen S, Salay TM, Alaparthy S, Grosso JF, Korman AJ, Parker SM, Agrawal S, Goldberg SM, Pardoll DM, Gupta A, Wigginton JM: Safety and activity of anti-PD-L1 antibody in patients with advanced cancer. N Engl J Med 2012;366: 2455-2465.

3 Mellman I, Coukos G, Dranoff G: Cancer immunotherapy comes of age. Nature 2011;480: 480-489.

4 Kirkwood JM, Butterfield LH, Tarhini AA, Zarour H, Kalinski P, Ferrone S: Immunotherapy of cancer in 2012. CA Cancer J Clin 2012;62:309-335.

5 Ishida Y, Agata Y, Shibahara K, Honjo T: Induced expression of PD-1, a novel member of the immunoglobulin gene superfamily, upon programmed cell death. EMBO J 1992;11: 3887-3895.

6 Freeman GJ, Long AJ, Iwai Y, Bourque K, Chernova T, Nishimura H, Fitz LJ, Malenkovich N, Okazaki T, Byrne MC, Horton HF, Fouser L, Carter L, Ling V, Bowman MR, Carreno BM, Collins M, Wood CR, Honjo T: Engagement of the PD-1 immunoinhibitory receptor by a novel B7 family member leads to negative regulation of lymphocyte activation. J Exp Med 2000;192:1027-1034.

7 Latchman Y, Wood CR, Chernova T, Chaudhary D, Borde M, Chernova I, Iwai Y, Long AJ, Brown JA, Nunes R, Greenfield EA, Bourque K, Boussiotis VA, Carter LL, Carreno BM, Malenkovich N, Nishimura H, Okazaki T, Honjo T, Sharpe AH, Freeman GJ: PD$\mathrm{L} 2$ is a second ligand for PD- 1 and inhibits T cell activation. Nat Immunol 2001;2:261-268.

8 Iwai Y, Ishida M, Tanaka Y, Okazaki T, Honjo T, Minato N: Involvement of PD-L1 on tumor cells in the escape from host immune system and tumor immunotherapy by PD-L1 blockade. Proc Natl Acad Sci USA 2002;99: 12293-12297.

9 Krummel MF, Allison JP: CD28 and CTLA-4 have opposing effects on the response of $\mathrm{T}$ cells to stimulation. J Exp Med 1995;182:459465.

10 Leach DR, Krummel MF, Allison JP: Enhancement of antitumor immunity by CTLA4 blockade. Science 1996;271:1734-1736.

11 Sharma P, Allison JP: The future of immune checkpoint therapy. Science 2015;348:56-61.
12 Chen DS, Mellman I: Oncology meets immunology: the cancer-immunity cycle. Immunity 2013;39:1-10.

13 Sznol M, Chen L: Antagonist antibodies to PD-1 and B7-H1 (PD-L1) in the treatment of advanced human cancer. Clin Cancer Res 2013;19:1021-1034.

14 Herbst RS, Soria JC, Kowanetz M, Fine GD, Hamid O, Gordon MS, Sosman JA, McDermott DF, Powderly JD, Gettinger SN, Kohrt HE, Horn L, Lawrence DP, Rost S, Leabman M, Xiao Y, Mokatrin A, Koeppen H, Hegde PS, Mellman I, Chen DS, Hodi FS: Predictive correlates of response to the anti-PD-L1 antibody MPDL3280A in cancer patients. Nature 2014;515:563-567.

15 Shih K, Arkenau HT, Infante JR: Clinical impact of checkpoint inhibitors as novel cancer therapies. Drugs 2014;74:1993-2013.

16 Philips GK, Atkins M: Therapeutic uses of anti-PD-1 and anti-PD-L1 antibodies. Int Immunol 2015;27:39-46.

17 Mahoney KM, Freeman GJ, McDermott DF: The next immune-checkpoint inhibitors: PD-1/PD-L1 blockade in melanoma. Clin Ther 2015;37:764-782.

18 Harshman LC, Drake CG, Wargo JA, Sharma $\mathrm{P}$, Bhardwaj N: Cancer immunotherapy highlights from the 2014 ASCO meeting. Cancer Immunol Res 2014;2:714-719.

19 Topalian SL, Drake CG, Pardoll DM: Targeting the PD-1/B7-H1(PD-L1) pathway to activate anti-tumor immunity. Curr Opin Immunol 2012;24:207-212.

20 Merelli B, Massi D, Cattaneo L, Mandala M: Targeting the PD1/PD-L1 axis in melanoma: biological rationale, clinical challenges and opportunities. Crit Rev Oncol Hematol 2014; 89:140-165.

21 Le DT, Uram JN, Wang H, Bartlett BR, Kemberling $\mathrm{H}$, Eyring AD, Skora AD, Luber BS, Azad NS, Laheru D, Biedrzycki B, Donehower RC, Zaheer A, Fisher GA, Crocenzi TS, Lee JJ, Duffy SM, Goldberg RM, de la Chapelle A, Koshiji M, Bhaijee F, Huebner T, Hruban RH, Wood LD, Cuka N, Pardoll DM, Papadopoulos N, Kinzler KW, Zhou S, Cornish TC, Taube JM, Anders RA, Eshleman JR, Vogelstein B, Diaz LA Jr: PD-1 blockade in tumors with mismatch-repair deficiency. N Engl J Med 2015;372:2509-2520.

22 Droeser RA, Hirt C, Viehl CT, Frey DM, Nebiker C, Huber X, Zlobec I, EppenbergerCastori S, Tzankov A, Rosso R, Zuber M, Muraro MG, Amicarella F, Cremonesi E, Heberer M, Iezzi G, Lugli A, Terracciano L, Sconocchia G, Oertli D, Spagnoli GC, Tornillo L: Clinical impact of programmed cell death ligand 1 expression in colorectal cancer. Eur J Cancer 2013;49:2233-2242.

23 Ribas A: Tumor immunotherapy directed at PD-1. N Engl J Med 2012;366:2517-2519.

24 Hamid O, Robert C, Daud A, Hodi FS, Hwu WJ, Kefford R, Wolchok JD, Hersey P, Joseph RW, Weber JS, Dronca R, Gangadhar TC,
Patnaik A, Zarour H, Joshua AM, Gergich K, Elassaiss-Schaap J, Algazi A, Mateus C, Boasberg P, Tumeh PC, Chmielowski B, Ebbinghaus SW, Li XN, Kang SP, Ribas A: Safety and tumor responses with lambrolizumab (antiPD-1) in melanoma. N Engl J Med 2013;369: 134-144.

25 Gao Q, Wang XY, Qiu SJ, Yamato I, Sho M, Nakajima Y, Zhou J, Li BZ, Shi YH, Xiao YS, $\mathrm{Xu}$ Y, Fan J: Overexpression of PD-L1 significantly associates with tumor aggressiveness and postoperative recurrence in human hepatocellular carcinoma. Clin Cancer Res 2009; 15:971-979.

26 Larkin J, Chiarion-Sileni V, Gonzalez R, Grob JJ, Cowey CL, Lao CD, Schadendorf D, Dummer R, Smylie M, Rutkowski P, Ferrucci PF, Hill A, Wagstaff J, Carlino MS, Haanen JB, Maio M, Marquez-Rodas I, McArthur GA, Ascierto PA, Long GV, Callahan MK, Postow MA, Grossmann K, Sznol M, Dreno B, Bastholt L, Yang A, Rollin LM, Horak C, Hodi FS, Wolchok JD: Combined nivolumab and ipilimumab or monotherapy in untreated melanoma. N Engl J Med 2015; 373:23-34.

27 Duffy A, Makarova-Rusher OV, Pratt D, Kleiner DE, Ulahannan S, Mabry D, Fioravanti S, Walker M, Carey S, Figg WD, Steinberg SM, Anderson V, Levy E, Krishnasamy V, Wood BJ, Greten TF: Tremelimumab: a monoclonal antibody against CTLA-4 in combination with subtotal ablation (trans catheter arterial chemoembolization (TACE), radiofrequency ablation (RFA) or cryoablation) in patients with hepatocellular carcinoma (HCC) and biliary tract carcinoma (BTC). J Clin Oncol 2016;34(suppl):abstr 4073.

28 Brahmer JR, Drake CG, Wollner I, Powderly JD, Picus J, Sharfman WH, Stankevich E, Pons A, Salay TM, McMiller TL, Gilson MM, Wang C, Selby M, Taube JM, Anders R, Chen L, Korman AJ, Pardoll DM, Lowy I, Topalian SL: Phase I study of single-agent anti-programmed death-1 (MDX-1106) in refractory solid tumors: safety, clinical activity, pharmacodynamics, and immunologic correlates. J Clin Oncol 2010;28:3167-3175.

29 Taube JM, Anders RA, Young GD, Xu H, Sharma R, McMiller TL, Chen S, Klein AP, Pardoll DM, Topalian SL, Chen L: Colocalization of inflammatory response with $\mathrm{B} 7-\mathrm{H} 1$ expression in human melanocytic lesions supports an adaptive resistance mechanism of immune escape. Sci Transl Med 2012;4: $127 \mathrm{ra3} 7$.

30 Tochio H, Sugahara M, Imai Y, Tei H, Suginoshita Y, Imawsaki N, Sasaki I, Hamada M, Minowa K, Inokuma T, Kudo M: Hyperenhanced rim surrounding liver metastatic tumors in the postvascular phase of Sonazoidenhanced ultrasonography: a histological indication of the presence of Kupffer cells. Oncology 2015;89(suppl 2):33-41.
Immune Checkpoint Inhibitors for Hepatocellular Carcinoma
Oncology 2017;92(suppl 1):50-62 DOI: $10.1159 / 000451016$ 
31 Michot JM, Bigenwald C, Champiat S, Collins M, Carbonnel F, Postel-Vinay S, Berdelou A, Varga A, Bahleda R, Hollebecque A, Massard C, Fuerea A, Ribrag V, Gazzah A, Armand JP, Amellal N, Angevin E, Noel N, Boutros C, Mateus C, Robert C, Soria JC, Marabelle A, Lambotte O: Immune-related adverse events with immune checkpoint blockade: a comprehensive review. Eur J Cancer 2016;54:139148.

32 El-Khoueiry A, Melero I, Crocenzi TS: Phase I/II safety and antitumor activity of nivolumab in patients with advanced hepatocellular carcinoma (HCC): CA209-040. J Clin Oncol 2015;33(suppl):abstr LBA101.

33 Sangro B, Gomez-Martin C, de la Mata M, Inarrairaegui $\mathrm{M}$, Garralda $\mathrm{E}$, Barrera P, Riezu-Boj JI, Larrea E, Alfaro C, Sarobe P, Lasarte JJ, Perez-Gracia JL, Melero I, Prieto J: A clinical trial of CTLA-4 blockade with tremelimumab in patients with hepatocellular carcinoma and chronic hepatitis C. J Hepatol 2013; 59:81-88.
34 Kudo M: Surveillance, diagnosis, treatment, and outcome of liver cancer in Japan. Liver Cancer 2015;4:39-50.

35 Poon RT, Cheung TT, Kwok PC, Lee AS, Li TW, Loke KL, Chan SL, Cheung MT, Lai TW, Cheung CC, Cheung FY, Loo CK, But YK, Hsu SJ, Yu SC, Yau T: Hong Kong consensus recommendations on the management of hepatocellular carcinoma. Liver Cancer 2015;4: 51-69.

36 Kudo M: Locoregional therapy for hepatocellular carcinoma. Liver Cancer 2015;4:163164.

37 Kang TW: Recent advances in tumor ablation for hepatocellular carcinoma. Liver Cancer 2015;4:176-187.

38 Lencioni R, de Baere T, Martin RC, Nutting $\mathrm{CW}$, Narayanan G: Image-guided ablation of malignant liver tumors: recommendations for clinical validation of novel thermal and non-thermal technologies - a Western perspective. Liver Cancer 2015;4:208-214.

39 Raoul JL, Gilabert M, Piana G: How to define transarterial chemoembolization failure or refractoriness: a European perspective. Liver Cancer 2014;3:119-124.
40 Tsurusaki M, Murakami T: Surgical and locoregional therapy of HCC: TACE. Liver Cancer 2015;4:165-175.

41 Arizumi T, Ueshima K, Minami T, Kono M, Chishina H, Takita M, Kitai S, Inoue T, Yada N, Hagiwara S, Minami Y, Sakurai T, Nishida N, Kudo M: Effectiveness of sorafenib in patients with transcatheter arterial chemoembolization (TACE) refractory and intermediate-stage hepatocellular carcinoma. Liver Cancer 2015;4:253-262.

42 Sangro B, Melero I, Yau TC, Hsu C, Kudo M, Crocenzi TS, Kim TY, Choo SP, Trojan J, Meyer T, Kang YK, Anderson J, Dela Cruz C, Lang L, Neely J, El-Khoueiry AB: Safety and antitumor activity of nivolumab (nivo) in patients (pts) with advanced hepatocellular carcinoma (HCC): interim analysis of dose-expansion cohorts from the phase $1 / 2$ CheckMate-040 study. J Clin Oncol 2016; 34(suppl):abstr 4078 